\title{
$X$ Chromosome Inactivation and Female Predisposition to Autoimmunity
}

\author{
Tayfun Ozcelik
}

Published online: 21 December 2007

(C) Humana Press Inc. 2007

Keywords Autoimmune diseases - Female predisposition . Mosaicism $\cdot \mathrm{X}$ chromosome inactivation

\section{Introduction}

The human $\mathrm{X}$ chromosome is the favorite chromosome of many geneticists because of its peculiar inheritance pattern and unique biology. The peculiar inheritance pattern stems from its hemizygosity in males and gives rise to a disproportionately high number of Mendelian diseases associated with a human chromosome. As high as $70 \%$ of the genes with a known function on the $\mathrm{X}$ are associated with disease phenotypes. The unique biology, termed Xinactivation, describes the transcriptional silencing of one of its copies in females. A substantial deal of sex differences in health issues has its origins in the genes on the $\mathrm{X}$ chromosomes and the $\mathrm{X}$-inactivation process [1]. For example, a single copy of $\mathrm{X}$ chromosome in males leads to their vulnerability to X-linked diseases, such as X-linked immunological diseases (Bruton agammaglobulinemia and Wiskott-Aldrich syndrome), Duchenne muscular dystrophy, or a variety of X-linked mental retardation syndromes, such as fragile $\mathrm{X}$ syndrome.

\footnotetext{
T. Ozcelik $(\bowtie)$
}

Department of Molecular Biology and Genetics,

Faculty of Science, and Institute for Materials Science and

Nanotechnology (UNAM), Bilkent University,

Bilkent, Ankara 06800, Turkey

e-mail: tozcelik@fen.bilkent.edu.tr

\section{Chromosome and Autoimmune Diseases}

The $\mathrm{X}$ chromosome is increasingly being more implicated in the function of the immune system and the development of autoimmune diseases. For example, forkhead box 3 on $\mathrm{Xp} 11.23$ is a member of the forkhead-winged-helix family of transcriptional regulators. It has a central role in T-cell biology, and its germ-line mutations are associated with Xlinked autoimmunity-allergic dysregulation syndrome also known as immune dysregulation, polyendocrinopathy, enteropathy, $\mathrm{X}$-linked syndrome [2, 3]. $\mathrm{X}$ chromosome is home to 32 genes, which have a melanoma antigen (MAGE) domain. Only four other $M A G E$ genes have been reported in the rest of the genome [4]. The $M A G E$ gene products are members of the cancer-testis antigen group, and they are potential targets for tumor immunotherapy [5]. Structural and numerical abnormalities of the $\mathrm{X}$ chromosome have been implicated in autoimmunity. For example, $\mathrm{X}$ autosome translocations and deletions of the $\mathrm{X}$ are associated with premature ovarian failure [6]. Patients with monosomy X (Turner's syndrome) often manifest autoimmune features [7].

\section{Female Preponderance in Autoimmune Diseases}

It has been recognized more than a century ago that women are more affected by autoimmune diseases than men [8]. The most striking sex differences are observed in scleroderma, autoimmune thyroid disease (Hashimoto's thyroiditis and Graves' disease), systemic lupus erythematosus, and Sjögren syndrome, in which the patient population is greater than $80 \%$ women. Other diseases such as rheumatoid arthritis, multiple sclerosis, and myasthenia gravis are 
relatively more common in women. And finally, in some diseases, such as insulin-dependent diabetes mellitus, subgroups characterized by distinct clinical manifestations may have female preponderance.

\section{Kast-Stewart Hypothesis}

Paths to understanding the genetic basis of autoimmune diseases have shown that simple Mendelian traits arising from single-gene mutations and complex traits resulting from interactions between multiple genotypes and the environment contribute to the breakdown of self-tolerance. Important environmental factors include pathogen exposure, pregnancy, and lifestyle. Despite significant advances, our present day understanding of the mechanisms of selftolerance and its breakdown is not complete, and novel mechanisms including those other than classical patterns of inheritance may play a critical role. One such mechanism, first hypothesized by Kast [9] and further developed by Stewart [10], is disturbances in the $\mathrm{X}$ chromosome inactivation process. The "Kast-Stewart hypothesis" has its roots in two simple observations; first, an overwhelming majority of autoimmune diseases are exceedingly more prevalent in females and, second, X-inactivation is a fundamental biological regulation that is in effect only in women. X chromosome inactivation is an epigenetic event in early development that leads to the transcriptional silencing of one of the pair of $\mathrm{X}$ chromosomes [11]. Therefore, $\mathrm{X}$ chromosome inherited by either parent is silenced at random, and normal women are thus a mosaic of two cell populations [1]. Although the attractive KastStewart hypothesis caught the attention of investigators working on autoimmune diseases, $\mathrm{X}$-inactivation patterns comparable to those of control women were observed in peripheral blood from female patients with systemic lupus erythematosus, juvenile diabetes, multiple sclerosis, and juvenile rheumatoid arthritis [12].

\section{X-Inactivation in Scleroderma}

While working on a male patient with classic Rett syndrome [13] and reviewing related literature on mosaicism [14], the author of this article suspected that extremely skewed X-inactivation, especially in hematopoietic stem cells, could be involved in the pathogenesis of scleroderma (systemic sclerosis). The focus on scleroderma has its roots on reports $[15,16]$ which raise the possibility that localized scleroderma, including the linear and frontal or frontoparietal (en coup de sabre) forms, may follow the lines of Blaschko [17]. Localized scleroderma is an autoimmune disorder, [18-20] and interestingly Blaschko's lines define dermatome areas which are thought to derive from a single $\mathrm{X}$-inactivation derivative [21-23]. To test the potential involvement of skewed X-inactivation in the pathogenesis of scleroderma, we analyzed the methylation status of a highly polymorphic CAG repeat in the androgen receptor gene and demonstrated that X-inactivation mosaicism is extremely skewed in the blood but not in the skin lesions of nearly half of a group of 55 females with scleroderma. This was the first study that established an association between $\mathrm{X}$-inactivation and female predisposition to autoimmunity [24]. An extension of this study, which investigates the parental origin of the inactive $\mathrm{X}$ chromosome, is presented in the accompanying manuscript [25].

\section{X-Inactivation in other Female Prevalent Autoimmune Diseases}

Following the publication of the scleroderma study, several studies that analyze X-inactivation patterns in femaleprevalent autoimmune diseases have been initiated by our group and others. According to published results, significantly increased proportions of patients with autoimmune thyroid diseases [26, 27], preeclampsia [28], and premature ovarian failure [29] display extremely skewed X chromosome inactivation, when compared to controls (Table 1). However, skewing in blood cells was not observed in individuals with primary biliary cirrhosis [30] and Sjögren's syndrome (unpublished observations), which may indicate that this is probably not a factor in all autoimmune diseases.

Table $1 \mathrm{X}$-inactivation patterns in patients with autoimmune diseases and controls

\begin{tabular}{llll}
\hline & \multicolumn{3}{l}{ Degree of skewing, No. (\%) observed } \\
\cline { 2 - 4 } & $90+$ & $80-89$ & $50-79$ \\
\hline Disease & & & \\
SSc-TR $(n=70)[24]$ & $27(49.1)$ & $8(14.5)$ & $20(36.4)$ \\
SSc-US $(n=125)[25]$ & $17(18.1)$ & $15(16.0)$ & $62(66.0)$ \\
AITD-TR $(n=110)[26]$ & $16(19.3)$ & $12(14.5)$ & $55(66.2)$ \\
AITD-Scand. $(n=40)[27]$ & $5(15.6)$ & $6(18.8)$ & $21(65.6)$ \\
PEE-TR $(n=67)[28]$ & $10(21.7)$ & $6(13.0)$ & $30(65.2)$ \\
POF-JP $(n=43)[29]$ & $5(18.5)$ & $9(33.3)$ & $13(48.1)$ \\
Sjögren-TR $(n=51)$ & $1(3.1)$ & $3(9.1)$ & $29(87.8)$ \\
Controls & & & \\
Children-TR $(n=92)$ & $2(2.8)$ & $6(8.3)$ & $64(88.9)$ \\
Newborn-TR $(n=91)$ & $2(3.8)$ & $2(3.8)$ & $48(92.3)$ \\
Newborn-US $(n=590)[42]$ & $4(0.7)$ & $29(4.9)$ & $557(94.4)$ \\
Adult-TR $(n=160)[24]$ & $3(2.4)$ & $7(5.6)$ & $114(91.9)$ \\
Adult-US $(n=415)[42]$ & $22(5.3)$ & $59(14.2)$ & $334(80.5)$ \\
\hline
\end{tabular}

SSc Scleroderma; AITD autoimmune thyroid diseases; PEE preeclampsia; $P O F$ premature ovarian failure; TR Turkey; US United States; Scand. Scandinavia; JP Japan 
In light of the known causes of primary biliary cirrhosis, lack of association is not an unexpected finding. Initiation of autoimmunity in this disease is most probably due to molecular mimicry [31].

\section{The Cause of Skewed X-Inactivation}

At present, we do not know the nature of the relationship between skewed patterns of X-inactivation and autoimmune diseases. However, two possibilities could be considered: skewing may arise as a result of breakdown in selftolerance, or breakdown of self-tolerance could be the result of skewing. We believe the latter is more likely simply because the degree of skewing is at the extreme of 95:5 or 100:0 in the majority of the patients. If the skewing were to arise as a result of an autoimmune reaction in the body, then the ratios would more likely be in the milder ranges. Monosomy $\mathrm{X}$ has been reported as a common finding in autoimmune diseases including scleroderma and autoimmune thyroiditis [32]. Could this factor influence the interpretation of the genotyping results as skewed Xinactivation? We find this possibility highly unlikely because skewing is at the extreme range. Therefore, the attractive "haploinsufficiency hypothesis" [33] may not apply to scleroderma and autoimmune thyroiditis. It has been proposed that demethylation of the inactive $\mathrm{X}$ chromosome may explain the female predilection of lupus [34]. This is a very interesting proposal, and it could be extrapolated to a "diploid overexpression hypothesis," which has the potential to explain why autoimmune diseases are more prevalent in females. But we find it difficult to attribute our extremely skewed ratios to generalized methylation defects because then the demethylation process should be a widespread event on the X, affecting the expression levels of many genes including androgen receptor. However, expression profiling did not reveal a global increase of X-linked genes in scleroderma $[35,36]$. Based on these considerations, we conclude that deleterious $\mathrm{X}$-linked mutations or $\mathrm{X}$ chromosome rearrangements and their differential expression patterns could provide a disadvantage to affected blood cells and lead to skewed X-inactivation. A circumstantial evidence in support of this explanation could be the increased incidence of recurrent spontaneous abortions in the extremely skewed patients in both scleroderma [24] and autoimmune thyroiditis [26]. Recurrent spontaneous abortions are associated with skewed X-inactivation [37, 38], and an association between autoimmune diseases and recurrent spontaneous abortions has been reported [39].

A key point to consider at this point is the location of these putative $\mathrm{X}$-linked mutations. We propose that they do not need to be at a certain gene or locus on the chromosome. On the contrary, any mutation that affects the viability of the cell could lead to skewed X-inactivation. In addition, $\mathrm{X}$-autosomal translocations, which fall within and outside genes [40] or other X chromosome aberrations, could affect the $\mathrm{X}$-inactivation ratios. Therefore, female predisposition to autoimmunity could be initiated by a variety of $\mathrm{X}$ chromosomal events including a single mutation in a very rich repertoire of genes. This may also explain why despite the extensive linkage genome scans, $\mathrm{X}$ chromosome is not clearly implicated in familial cases of autoimmune thyroid diseases, [41] or to that effect why a major locus for autoimmunity proves to be so difficult to find in the genome. It is probably time to consider "loss of mosaicism" for X-linked gene expression as the first step of the cellular events that lead to breakdown of self-tolerance in females.

\section{Future Perspectives}

Although extremely skewed X-inactivation is rare and it is associated with autoimmune diseases, it does not lead to the breakdown of self-tolerance in all women. We believe this point is of paramount importance in identifying the putative $\mathrm{X}$-linked genes associated with autoimmune diseases and propose that breakdown of self-tolerance requires the coinheritance of two distinct events on the $\mathrm{X}$ chromosome: first, an X-linked mutation leading to "loss of mosaicism" and second "heterozygosity for allelic variants of the putative critical genes". Developing research strategies in line with the above proposed mechanisms could prove to be very fruitful in understanding the molecular determinants of autoimmunity and identify potential targets for therapy.

Acknowledgements I would like to thank Iclal Ozcelik for critical reading of the manuscript. This work is supported by grants from the Scientific and Technical Research Council of Turkey-TUBITAKSBAG 3334, International Centre for Genetic Engineering and Biotechnology - CGEB-CRP/TUR04-01, and Bilkent University Research Fund.

\section{References}

1. Migeon BR (2006) The role of X inactivation and cellular mosaicism in women's health and sex-specific diseases. JAMA 295:1428-1433

2. Chatila TA, Blaeser F, Ho N, Lederman HM, Voulgaropoulos C, Helms C, Bowcock AM (2000) JM2, encoding a fork head-related protein, is mutated in X-linked autoimmunity-allergic disregulation (sic) syndrome. J Clin Invest 106:R75-R81

3. Bennett CL, Christie J, Ramsdell F, Brunkow ME, Ferguson PJ, Whitesell L, Kelly TE, Saulsbury FT, Chance PF, Ochs HD (2001) The immune dysregulation, polyendocrinopathy, enteropathy, X-linked syndrome (IPEX) is caused by mutations of FOXP3. Nat Genet 27:20-21 
4. Ross MT, Grafham DV, Coffrey AJ et al (2005) The DNA sequence of the human X chromosome. Nature 434:325-337

5. Scanlan MJ, Simpson AJ, Old LJ (2004) The cancer/testis genes: review, standardization, and commentary. Cancer Immun 4:1

6. Schlessinger D, Herrera L, Crisponi L, Mumm S, Percdesepe A, Pellegrini M, Pilia G, Forabosco A (2002) Genes and translocations involved in POF. Am J Med Genet 111:328-333

7. Ranke MB, Saenger P (2001) Turner's syndrome. Lancet 358:309-314

8. Whitacre CC (2001) Sex differences in autoimmune disease. Nat Immunol 2:777-780

9. Kast RE (1977) Predominance of autoimmune and rheumatic diseases in females. J Rheumatol 4:288-292

10. Stewart JJ (1998) The female X-inactivation mosaic in systemic lupus erythematosus. Immunol Today 19:352-357

11. Lyon MF (1961) Gene action in the X-chromosome of the mouse (Mus musculus L). Nature 190:372-373

12. Chitnis S, Monteiro J, Glass D et al (2000) The role of Xchromosome inactivation in female predisposition to autoimmunity. Arthritis Res 2:399-406

13. Topcu M, Akyerli C, Sayi A, Toruner GA, Kocoglu SR, Cimbis M, Ozcelik T (2002) Somatic mosaicism for a MECP2 mutation associated with classic Rett syndrome in a boy. Eur J Hum Genet 10:77-81

14. Ozcelik T (2002) Uncovering the complex mysteries of mosaicism. Nature 417:588

15. Jackson R (1976) The lines of Blaschko: a review and reconsideration: observations of the cause of certain unusual linear conditions of the skin. Br J Dermatol 95:349-360

16. Soma Y, Fujimoto M (1998) Frontoparietal scleroderma (en coup de sabre) following Blaschko's lines. J Am Acad Dermatol 38:366-368

17. Blaschko A (1901) Die Nervenverteilung in der Haut in ihrer Beziehung zu den Erkrankungen der Haut. Beilage zu den Verhandlungen der Deutschen Dermatologischen Gesellschaft VII Congress, Breslau

18. McKeon FD, Tuffanelli DL, Fukuyama K, Kirschner MW (1983) Autoimmune response directed against conserved determinants of nuclear envelope proteins in a patient with linear scleroderma. Proc Natl Acad Sci 80:4374-4378

19. Nelson AM (1996) Localized forms of scleroderma, including morphea, linear scleroderma, and eosinophilic fasciitis. Curr Opin Rheumatol 8:473-476

20. Takehara K, Sato S (2005) Localized scleroderma is an autoimmune disorder. Rheumatology 44:274-279

21. Happle R (1985) Lyonization and the lines of Blaschko. Hum Genet 70:200-206

22. Happle R (1993) Mosaicism in human skin. Understanding the patterns and mechanisms. Arch Dermatol 129:1460-1470

23. Happle R (2006) X-chromosome inactivation: role in skin disease expression. Acta Paediatr Suppl 95:16-23

24. Ozbalkan Z, Bagislar S, Kiraz S, Akyerli CB, Ozer THE, Yavuz S, Birlik AM, Calguneri M, Ozcelik T (2005) Skewed X chromosome inactivation in blood cells of women with scleroderma. Arthritis Rheum 52:1564-1570

25. Uz E, Loubiere LS, Gadi VK, Ozbalkan Z, Stewart JJ, Nelson JL, Ozcelik T (2007) Extremely skewed X chromosome inactivation in scleroderma. Clin Rev Allergy Immunol (in press)

26. Ozcelik T, Uz E, Akyerli CB, Bagislar S, Mustafa CA, Gursoy A, Akarsu N, Toruner G, Kamel N, Gullu S (2006) Evidence from autoimmune thyroiditis of skewed X-chromosome inactivation in female predisposition to autoimmunity. Eur J Hum Genet 14:791-797
27. Brix TH, Knudsen GP, Kristiansen M, Kyvik KO, Orstavik KH, Hegedus L (2005) High frequency of skewed X-chromosome inactivation in females with autoimmune thyroid disease: a possible explanation for the female predisposition to thyroid autoimmunity. J Clin Endocrinol Metab 90:5949-5953

28. Uz E, Dolen I, Al AR, Ozcelik T (2007) Extremely skewed $\mathrm{X}$-chromosome inactivation is increased in pre-eclampsia. Hum Genet 121:101-105

29. Sato K, Uehara S, Hashiyada M, Nabeshima H, Sugawara J, Terada Y, Yaegashi N, Okamura K (2004) Genetic significance of skewed $\mathrm{X}$-chromosome inactivation in premature ovarian failure. Am J Med Genet 130A:240-244

30. Invernizzi P, Selmi C, Miozzo M, Bianchi I, Maitz S, Lleo A, Rossio R, Gershwin ME, Podda M (2006) The X choromosome in female predominant autoimmune diseases. Autoimmunity Reviews 93. Abstracts of Fifth International Congress on Autoimmunity, November 29-December 3, Sorrento, Italy. Available from www.elsevier.com/locate/autrev

31. Kaplan MM, Gershwin ME (2005) Primary biliary cirrhosis. N Engl J Med 353:1261-1273

32. Invernizzi P, Miozzo M, Selmi C et al (2005) X chromosome monosomy: a common mechanism for autoimmune diseases. J Immunol 175:575-578

33. Selmi C, Invernizzi P, Gershwin ME (2006) The X chromosome and systemic sclerosis. Curr Opin Rheumatol 18:601-605

34. Richardson B, Tesmer L, Wu A, Ray D, Lu Q (2006) X chromosome reactivation in lupus. Autoimmunity Reviews, Abstracts of the 5th International Congress on Autoimmunity, November 29-December 3, Sorrento, Italy. Available from www. elsevier.com/locate/autrev

35. Gardner H, Shearstone JR, Bandaru R, Crowell T, Lynes M, Trojanowska M, Pannu J, Smith E, Jablonska S, Blaszczyk M, Tan FK, Mayes MD (2006) Gene profiling of scleroderma skin reveals robust signatures of disease that are imperfectly reflected in the transcript profiles of explanted fibroblasts. Arthritis Rheum 54:1961-1973

36. Tan FK, Zhou X, Mayes MD, Gourh P, Guo X, Marcum C, Jin L, Arnett FC Jr (2006) Signatures of differentially regulated interferon gene expression and vasculotrophism in the peripheral blood cells of systemic sclerosis patients. Rheumatology 45:694-702

37. Lanasa MC, Hogge WA, Kubick C, Blancato J, Hoffman EP (1999) Highly skewed X-chromosome inactivation is associated with idiopathic recurrent spontaneous abortion. Am J Hum Genet 65:252-254

38. Bagislar S, Ustuner I, Cengiz B, Soylemez F, Akyerli CB, Ceylaner S, Ceylaner G, Acar A, Ozcelik T (2006) Extremely skewed Xchromosome inactivation patterns in women with recurrent spontaneous abortion. Aust N Z J Obstet Gynaecol 46:384-387

39. Shelton AJ, Harger JH, Dorman JS, Kuller LH, LaPorte RE, Gill TJ (1994) Association between familial autoimmune diseases and recurrent spontaneous abortions. J Reprod Immunol 32:82-87

40. Mumm S, Herrera L, Waeltz PW, Scardovi A, Nagaraja R, Esposito T, Schlessinger D, Rocchi M, Forabosco A (2001) X/ autosome translocations in the $\mathrm{Xq}$ critical region associated with premature ovarian failure fall within and outside genes. Genomics 76:30-36

41. Imrie H, Vaidya B, Perros P, Kelly WF, Toft AD, Young ET, Kendall-Taylor P, Pearce SH (2001) Evidence for a Graves' disease susceptibility locus at chromosome Xp11 in a United Kingdom population. J Clin Endocrinol Metab 86:626-630

42. Amos-Landgraf JM, Cottle A, Plenge RM, Friez M, Schwartz CE, Longshore J, Willard HF (2006) X chromosome-inactivation patterns of 1005 phenotypically unaffected females. Am J Hum Genet 79:493-499 